\title{
USO DE ABREVIATURAS EM UM LIVRO DE ASSENTOS DE CASAMENTOS DO SÉCULO XVIII DO SERTÃO DE BAIXO DO RIO SÃO FRANCISCO
}

\author{
USE OF ABBREVIATIONS IN A WEDDING SEATS BOOK OF THE XVIII \\ CENTURY IN THE SERTÃO DE BAIXO DO RIO SÃO FRANCISCO
}

\author{
Lécio Barbosa de Assis ${ }^{1}$ \\ Jorge Augusto Alves da Silva ${ }^{2}$ \\ Vera Pacheco ${ }^{3}$
}

\begin{abstract}
RESUMO: O presente estudo aborda o uso de abreviaturas no Livro n. ${ }^{\circ} 1$ dos assentos de casamentos da Freguesia de Santo Antônio do Urubu de baixo do Rio São Francisco (1719-1753), exarado por oito diferentes scriptores ao longo do recorte temporal estudado. Este trabalho apresentará uma breve descrição codicológica, bem como o levantamento da frequência do uso das abreviaturas, com o objetivo de revelar as tendências utilizadas na época em que o manuscrito foi produzido, como também, as peculiaridades de cada scriptor. Metodologicamente, para empreender este estudo, realizamos a (i) exploração das particularidades do suporte material do documento; (ii) leitura e transcrição a partir da reprodução fac-similar; (iii) sistematização do número de ocorrências e comparação das frequências de acordo com o sistema de classificação das abreviaturas com o auxílio da ferramenta computacional aplicada à Terminologia AntConc (2011) e (iv) reflexão filológicopaleográfica das abreviaturas e dos sinais de abreviações. Por meio do referencial teórico, buscamos trilhar os caminhos filológicos e paleográficos, recorrendo às obras de Bluteau (1728), Vieira (1871), Spina (1977), Acioli (1994), Núñez Contreras (1994), Cambraia (2005), Berwanger e Leal (2008) e Flexor (2008). Os resultados evidenciaram que o uso das abreviaturas, no documento analisado, seguia as tendências gerais da época, transmitidas pela tradição documental, embora as Constituições Primeiras do Arcebispado da Bahia (1719) orientavam que os registros paroquiais deveriam ser exarados por extenso para evitar enganos e dificuldades na leitura.
\end{abstract}

PALAVRAS-CHAVE: Assentos de casamentos. Codicologia. Paleografia. Filologia. Abreviaturas.

ABSTRACT: The present study addresses the use of abbreviations in Book $\mathrm{n} .^{\circ} 1$ of the wedding seats in the Freguesia de Santo Antônio do Urubu de baixo do Rio São Francisco (1719-1753), written by eight different scriptors throughout the studied time frame. This work will present a brief codicological description, as well as a survey of the frequency of the use of abbreviations, in order to reveal the trends used at the time the manuscript was produced, as well as the peculiarities of each scriptor. Methodologically, to undertake this study, we carried out (i) exploration of the particularities of the material of document support; (ii) reading and transcribing from the fac-similar edition; (iii) systematization of the number of occurrences and comparison of frequencies according to the abbreviation classification system with the aid of the computational tool applied to the AntConc Terminology (2011) and (iv) philological-paleographic reflection of the abbreviations and the abbreviation signs. Through the theoretical framework, we seek to follow the philological and paleographic paths, using the works of Bluteau (1728), Vieira (1871), Spina (1977), Acioli (1994), Núñez Contreras (1994), Cambraia (2005), Berwanger and Leal (2008) and Flexor (2008). The results showed that the use of abbreviations, in the document analyzed, followed the general trends of the time, transmitted by the documentary tradition, although the

\footnotetext{
1 Doutorando em Linguística pelo Programa de Pós-graduação em Linguística da Universidade Estadual do Sudoeste da Bahia-UESB; E-mail: falecomlecio@gmail.com; Orcid id: https://orcid.org/0000-0001-9343-6900.

2 Doutor em Linguística pela UFBA; Professor Pleno vinculado ao Departamento de Estudos Linguísticos e Literários da Universidade Estadual do Sudoeste da Bahia-UESB e ao Programa de Pós-graduação em Linguística e Profletras da Universidade Estadual do Sudoeste da Bahia; E-mail adavgvstvm@gmail.com; Orcid id: https://orcid.org/0000-0001-5884-2698.

${ }^{3}$ Doutora em Linguística pela Unicamp; Professora Plena vinculada ao Departamento de Estudos Linguísticos e Literários da Universidade Estadual do Sudoeste da Bahia (UESB) e ao Programa de Pós-graduação em Linguística e ao Profletras da Universidade Estadual do Sudoeste da Bahia (UESB); E-mail vera.pacheco@gmail.com; Orcid id: http://orcid.org/0000-0002-7986-7701.
} 
Volume 16 - Número 1 - jan/jul de 2021

Constituições Primeiras do Arcebispado da Bahia (1719) stated that parish records should be written out in full to avoid mistakes and reading difficulties.

KEYWORDS: Wedding seats. Codicology. Paleography. Philology. Abbreviations.

\section{Considerações iniciais}

Os registros paroquiais de casamentos, estabelecidos e padronizados a partir do Concílio Tridentino (1545-1563), são fontes documentais que possibilitam a combinação de estudos através de aspectos filológicos, paleográficos, codicológicos, fenômenos linguísticos e da historicidade dos textos, a partir das tradições que regem as formas textuais, além de revelar o contexto sócio-histórico de um determinado tempo e espaço.

O presente estudo objetiva discutir o uso de abreviaturas no Livro n. ${ }^{\circ} 1$ dos assentos de casamentos da Freguesia de Santo Antônio do Urubu de baixo do Rio São Francisco (17191753), com o propósito de responder a seguinte questão: por que os scriptores utilizavam palavras abreviadas nos assentos de casamentos, se o uso de abreviaturas eram contrárias às normas das Constituições Primeiras do Arcebispado da Bahia (1719)? A hipótese inicial para essa pergunta é que tais recursos refletiam, além do princípio da economia, as tendências utilizadas na época que seguiam a tradição documental.

Neste recorte, analisaremos as abreviaturas encontradas no Livro $n .^{\circ} 1$ dos assentos de casamentos da Matriz de Santo Antônio do Urubu de baixo do Rio São Francisco, freguesia fundada em 1718, na margem direita do Rio São Francisco, pertencente à Capitania de Sergipe d'El Rey, área que corresponde atualmente a região do norte da Bahia e do baixo São Francisco sergipano. A fonte documental faz parte de uma coleção de livros de registros paroquiais que estão sob a guarda da Cúria Diocesana de Bom Jesus da Lapa -BA, cujas reproduções fac-similares, utilizadas para este estudo, fazem parte do acervo do Grupo de Pesquisa Educação Patrimonial: mapeando acervos históricos e culturais de Bom Jesus da Lapa, vinculado à Universidade do Estado da Bahia-UNEB, Campus XVII.

A metodologia para o estudo das abreviaturas levou em consideração alguns passos para desenvolver a investigação, como a análise codicológica da fonte, observando os critérios propostos por Cambraia (2005), em seguida a leitura e transcrição do documento a partir da reprodução fac-similar e, posteriormente foram sistematizadas as palavras abreviadas e suas variações com o auxílio da ferramenta computacional AntConc ${ }^{4}$ (2011) que permite a geração de listas de palavras, cálculos estatísticos e análises de determinados termos em um corpus e a consulta e comparação das abreviaturas em obras de referência (BLUTEAU,1728; VIEIRA,1871; FLEXOR, 2008) para verificar se são equivalentes.

Ao abordar o Livro n. ${ }^{\circ} 1$ (1719-1753) da Freguesia de Santo Antônio do Urubu de baixo do Rio São Francisco através da exploração do suporte material e da leitura da reprodução fac-similar, observamos o uso frequente das abreviaturas, especialmente utilizada em palavras muito repetidas, entre elas, os topônimos, patronímicos e os pronomes de tratamento. Assim, levando em consideração que o uso de abreviaturas em textos antigos pode dificultar a leitura e que esse aspecto filológico-paleográfico é relevante para a análise da materialidade da escrita da época e importante para os estudiosos de manuscritos antigos, aventamos em realizar uma investigação que possa contribuir com os estudos linguísticos, sobretudo no sertão do São Francisco.

\footnotetext{
${ }^{4}$ https://www.laurenceanthony.net/software/antconc/
} 
Volume 16 - Número 1 - jan/jul de 2021

\section{Abreviaturas}

Raphael Bluteau (1728, p. 9), em seu Dicionário Vocabulario Portuguez e Latino, define a abreviatura como "modo de escrever, em que faltão algumas letras, que o leitor supre. $\S$ Cifras, finaes que representão as letras mais curtamente." Da mesma forma, Frei Domingos Vieira (1871, p. 35), nos diz em sua obra Grande Diccionario Portuguez ou Thesouro da Lingua Portugueza que as abreviaturas são palavras abreviadas, sinais, caracteres ou cifras que se empregam para escrever muito em pouco espaço ou tempo. Segundo o autor, o sistema de abreviatura foi inventado no Egito e adotado pelos gregos e depois transmitido aos romanos. A própria etimologia da palavra 'abreviatura' revela a brevidade da forma da escrita. Abreviar vem do verbo latino abreviare, composto por $a b$, de, e ireviare, encurtar, ou seja, encolher, apertar, estreitar, acanhar, reduzir, resumir, compendiar, representar com menor ponto, diminuir a quantidade de uma sílaba (VIEIRA, 1871, p.35).

Em consonância com as definições de Bluteau ( 1728) e Vieira (1871), o Professor João Eurípedes Gualandi Franklin Leal (1994, p. 9), em seu Glossário de Paleografia, nos diz que abreviatura é a "representação de palavra por meio de alguma ou algumas de suas letras ou sílabas" e de acordo com Marcotulio et al., na obra Filologia, história e língua: olhares sobre o português medieval, as abreviaturas são como "letras ou conjunto de letras que se empregam em textos escritos para representar de forma breve as palavras, até o mínimo possível, para que possam ser entendidas" (2018, p. 35).

Diante dessas considerações sobre a presença de abreviaturas em documentos antigos, podemos considerar que a frequência de seu uso era realizada, possivelmente, para facilitar a ação do scriptor que, com o propósito de ser breve, buscava a economia de tempo e espaço no ato de escrever. O filólogo Segismundo Spina (1977, p. 44), na obra Introdução à edótica: crítica textual, aponta que o sistema de abreviaturas utilizado na Idade Média teve sua profusão em razão da raridade e do custo elevado do material da escrita e que a chave da interpretação paleográfica de documentos antigos estava no conhecimento das abreviaturas.

Spina (1977, p. 45) registra que o uso das abreviaturas no final da república romana tornou-se de uso complicado, necessitando de intervenção do senado e dos imperadores para a proibição do seu uso. No reinado carolíngio, o abuso das abreviaturas começou a saturar os documentos, chegando ao ponto de, nos séculos XII e XIII, várias disposições serem baixadas para conter o problema em questão, até o abuso começar a diminuir com a implantação da letra cursiva que não permitia a profusão das abreviaturas. Em vários momentos da história, o uso das abreviaturas foi proibido (BERWANGER; LEAL, 2008, p. 91) e o uso e abuso de alguns sistemas abreviativos relacionam-se com a lei do mínimo esforço (SANCHEZ PRIETO, 2001, p. 161).

As formas abreviadas encontradas no livro de assentos de casamentos da Freguesia de Santo Antônio do Urubu de baixo do Rio São Francisco, século XVIII, apresentam esse fenômeno da redução dos elementos que obedece a um princípio da economia que se manifesta de forma contrária às tradições das Constituições Primeiras do Arcebispado da Bahia (1719) que recomendavam:

Conformando-nos com a disposição do Sagrado Concilio Tridentino (1) ordenamos, que no livro que no titulo 20 á num. 70 temos mandado haja para nelle se fazerem os assentos dos casados, se assentem (2) seus nomes, e de seus pais, e mãis, e das testemunhas que forem presentes, e dia, lugar, e Igreja, onde se receberão, tudo por lettra (3) ao comprido, e não por algarismo, ou abreviatura (4) pela maneira seguinte, por se evitarem os 
Volume 16 - Número 1 - jan/jul de 2021

enganos, que pelo contrario podem, e costumão succeder. (CONSTITUIÇÕES..., 1719, p. 130) (grifo nosso)

O texto das Constituições (1719) deixava evidente que os assentos de casamentos, assim, como dos outros sacramentos, deveriam ser exarados com clareza e por extenso para evitar enganos e, consequentemente, dificuldades na leitura. Nisso, concorda Flexor (2008, p. 9) que, ao relacionar o labor do pesquisador, ao consultar manuscritos antigos, defronta-se com várias dificuldades de leitura, entre elas, às abreviaturas.

No Manual de Paleografia: fundamentos e historia de la escritura latina hasta el siglo VIII, de Luis Núñez Contreras (1994, p.107-108), em uma seção dedicada ao uso das abreviaturas, o autor estabelece explicações não satisfatórias para o uso das abreviaturas no ato da escrita, seja por economia de tempo ou maior rapidez no ato de escrever. O autor explica que escrever de forma abreviada uma palavra pode levar mais tempo e exigir mais atenção do que se fossem escritas por extenso e em relação à economia do suporte utilizado, parece que não seria muito significativo.

Núñes Contreras (1994) ressalta que a representação frequente da mesma palavra no texto facilita sua leitura pela identificação mais representativa de seus elementos, a exemplo das letras iniciais e finais que são reconhecidas mais facilmente do que as intermediárias. Assim, o autor reconhece que as abreviaturas proporcionam uma síntese gráfica, favorecida pela lei do mínimo esforço quando se escreve e quando se lê, e a percepção sensorial das letras mais características e a totalidade das palavras são percebidas mais facilmente.

Como o uso da abreviatura é uma questão recorrente nos assentos de casamentos analisados, podemos relacionar a ideia geral do princípio de economia que justifica a necessidade de abreviatura, uma vez que foi encontrada um maior número de abreviaturas em palavras que têm maior recorrência nos textos do que aquelas que têm maior extensão.

A seguir, apresentaremos o sistema de abreviaturas proposto por Berwanger e Leal (2008, p. 63-64) e Flexor (2008, p.14) que se dividem em:

Notas tironianas - baseavam-se nas letras do alfabeto maiúsculo romano e os sinais eram utilizados em várias posições, por exemplo D'= Deus, DO”= dom. Foram pouco utilizadas em documentos luso-brasileiros e vigorou até o século XVI.

Siglas - as siglas são letras iniciais maiúsculas que representam as palavras completas, podendo ser simples ou reduplicadas para indicar o plural ou quando a letra é encontrada pelo menos por duas vezes na palavra. Por exemplo: $\mathrm{V}=$ verso; $\mathrm{D}=$ dom; $\mathrm{S}=$ santo; $\mathrm{RR}=$ Reverendos.

Abreviatura alfanumérica - representada pela combinação de números e letras. No corpus da pesquisa, apareceu apenas um exemplo no fólio $54 \mathrm{v}$. (Vistos estes aSentos em viz. $^{\text {am }}$ | aos 6 de 9 br. ${ }^{\circ}$ de 1744 annos Bapt. ${ }^{\text {a }}$ Viz. $\left.{ }^{\text {or }} \mathrm{g}^{\mathrm{al}}\right)$.

Abreviaturas por suspensão ou apócope - quando falta o final da palavra e esta fica inacabada, geralmente utilizada em palavras mais recorrentes. Por exemplo: escr. = escravo; fr. $=$ frei; sagr. $=$ sagrado.

Abreviaturas por contração ou por síncope - quando estão representados o início e o final da palavra. Por exemplo: Alfrz' = Alferes; Glz' = Gonçalves.

Abreviaturas com letras sobrescritas - a(s) última(s) letra(s) da palavra é/são colocada(s) em suspenção na letra inicial ou prefixo da palavra abreviada. Por exemplo: Ign. ${ }^{\text {co }}$ $=$ Ignácio; impedim. ${ }^{\text {to }}=$ impedimento; $\mathrm{m}{ }^{\mathrm{er}}=$ mulher.

Quanto aos sinais abreviativos, de acordo com Acioli (1994, p. 46), dividem-se em gerais e especiais. Os sinais gerais não tem valor fonológico e são representados pelo ponto, linha reta, linha curva e traço envolvente. Quanto aos sinais especiais, estes foram utilizados na escrita medieval e derivavam das notas tironianas. São sinais que têm valor fonológico e substituem uma letra ou agrupamento. $\mathrm{O}$ uso de sinais diacríticos são exemplos de sinais 
especiais, independentemente da posição em que apareçam, significam a ausência de uma sílaba ou de uma letra, por exemplo, podem indicar $/ \mathrm{m} / \mathrm{ou} / \mathrm{n} /$ ou ausência de letras, como em algú = algum; hú = hum; co'= com; p' = para, q' = que.

Além do sistema de classificação das abreviaturas e sinais abreviativos proposto por Acioli (1994), Berwanger e Leal (2008) e Flexor (2008), dois fenômenos léxico-semânticos envolvendo o uso das abreviaturas foram levantados por Pereira e Telles (1982): a polissemia e a parassinonímia. A polissemia apresenta a mesma forma abreviada para diferentes palavras, a exemplo de S. (São, Santo, Santa, Senhora). No entanto, a parassinonímia representa uma mesma palavra por diferentes formas de abreviar, como no exemplo, S. ${ }^{r}, \mathrm{Snn}^{\circ}$, Snr, Snr' para abreviar o pronome de tratamento Senhor. Esses dois fenômenos refletem a hesitação do scriptor no momento da escrita, evidenciada pela falta de normatização para a aplicação das abreviaturas.

Depois dessa breve explanação sobre as abreviaturas e sinais abreviativos, a próxima seção descreverá as características materiais da fonte documental selecionada para este estudo.

\section{Análise codicológica}

O estudo codicológico da fonte documental tomou como modelo o guia de descrição apresentado por Cambraia (2005, p. 28) em sua obra Introdução à crítica textual, que define a Codicologia como uma ciência que estuda os aspectos materiais ou técnica dos livros manuscritos.

O livro n..$^{\circ} 1$ (1719-1753) inicia-se com um termo de abertura, informando que se trata de um livro destinado aos assentos dos casados da Matriz de Santo Antônio do Urubu do Rio de São Francisco, começando no fólio 1 e aos assentos dos mortos, principiado no fólio 80 . O livro compõe-se de 138 fólios escritos em frente e verso, com exceção da folha de rosto e do fólio final. Embora escritas nos dois lados, as folhas são numeradas apenas no recto, no canto superior da margem direita, e rubricada com a assinatura da autoridade eclesiástica: "Pontes".

A capa da encadernação é feita em cartão e mede 315 × $215 \mathrm{~mm}$, como ilustra a

Figura 1. A lombada está deteriorada na parte superior e tem aproximadamente $280 \mathrm{~mm}$ e apresenta uma inscrição com a data-limite dos assentos de casamentos de 1720 a 1751 , embora no fólio 2 recto há dois assentos datados do ano de 1719, e outra para os assentos de óbitos, indicando a data de 1719 a 1753. A dimensão dos fólios é de 300 x $205 \mathrm{~mm}$. O suporte é composto de um papel de textura fina e de alta qualidade, sem pauta, apenas com piques equidistantes nas margens direita e esquerda para guiar os traços da justificação, provavelmente feito por um objeto que lembra um bico de pena, um compasso ou estilete. 
Volume 16 - Número 1 - jan/jul de 2021

Figura 1: Capa do livro

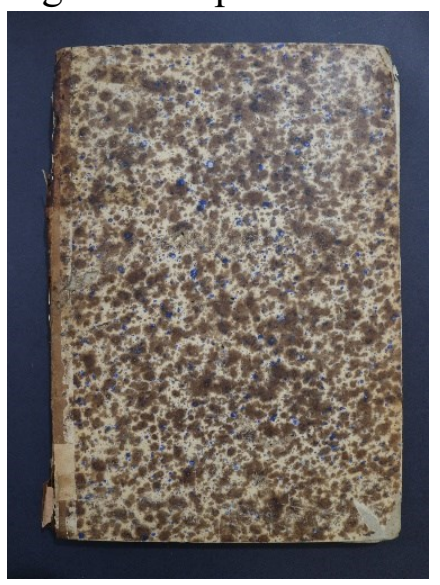

Foto: Lécio Barbosa de Assis
Figura 2: Dimensão da mancha e das margens

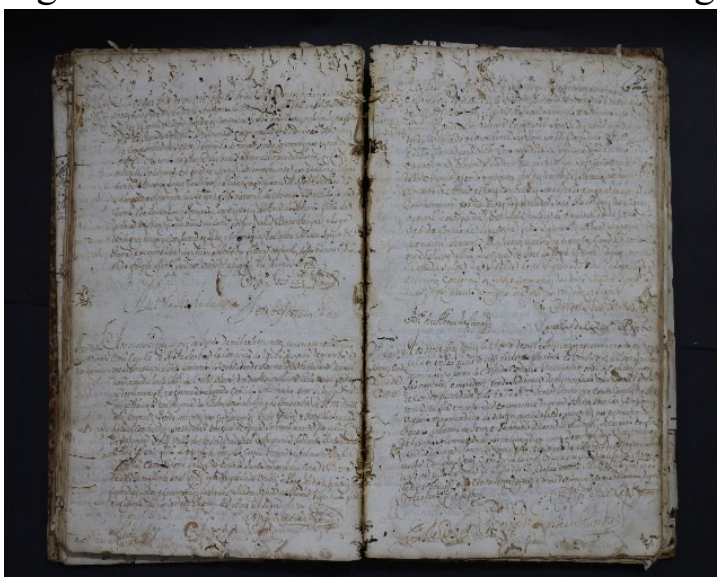

Foto: Lécio Barbosa de Assis

A mancha ou caixa de texto tem dimensão aproximada entre $270 \times 170 \mathrm{~mm}$ no recto $\mathrm{e}$ 280 x $150 \mathrm{~mm}$ no verso, ocupadas, em média, por 30 linhas, sem contar os espaços utilizados para as assinaturas do vigário e das testemunhas, como mostra a Figura 2. A extensão do texto dos assentos não era uniforme, embora seguia as tradições das Constituições Primeiras do Arcebispado da Bahia (1719), cada registro tinha suas características particulares. Além do registro dos assentos, as margens eram utilizadas para anotações adicionais, a exemplo dos nomes dos nubentes, utilizando a margem direita no recto e a margem esquerda no verso de cada fólio e também havia os reclames que ocupavam o canto direito da margem inferior. $\mathrm{O}$ reclame é a palavra final do fólio que é repetida no fólio seguinte com o objetivo de indicar a sequência dos fólios e da leitura.

O livro é escrito com tinta ferrogálica, de coloração amarronzada, com variações mais escuras ou mais claras ao longo do documento e em alguns casos, a coloração aproxima-se do preto. Em alguns fólios, há manchas e corrosão deixadas pela tinta, onde a concentração foi maior, além da migração que transferiu as imagens para o verso e para outros fólios do documento. Outros sinais de deterioração foram deixados por papirófagos, especialmente na parte superior, além de manchas de umidade percebidas desde o fólio 1 ao 17, além de uma mancha mais escura na parte inferior do livro, à direita no recto e à esquerda no verso que inicia no fólio 1 e vai diminuindo até desaparecer no fólio 9.

O termo de encerramento, localizado no verso do fólio 138, finaliza o documento informando que o referido livro serve aos assentos dos mortos da Matriz de Santo Antônio do Urubu do Rio de São Francisco, começando pela folha 80 e dos casados na folha 1, constando de 138 folhas numeradas e rubricadas, com local e data: " $\mathrm{B}^{\mathrm{a}} 4$ de Nobro de 1718 ". O livro foi competentemente aberto, numerado, rubricado e encerrado pela autoridade eclesiástica de acordo com as disposições canônicas, exercida pelo Vigário Geral e Visitador do Arcebispado.

A descrição codicológica teve o objetivo de fornecer informações sobre o suporte material da escrita a partir da exploração das particularidades do documento, apontando possibilidades e perspectivas de continuação do trabalho à luz dos pressupostos filológicopaleográficos. 


\section{Materiais e métodos}

A amostra das abreviaturas que constituem este estudo foi retirada dos 231 assentos de casamentos, contidos no Livro n. ${ }^{\text {o }} 1$ (1719-1753) da Freguesia de Santo Antônio do Urubu de baixo do Rio São Francisco, que contêm assentos de casamentos e de óbitos, sendo reservados, para este estudo, apenas os assentos de casamentos. Os registros eram feitos pelos vigários da paróquia, responsáveis pelo lançamento dos sacramentos realizados na freguesia. No recorte temporal em questão, evidenciamos 8 (oito) diferentes punhos, responsáveis pelo lançamento dos registros.

Quadro 1: Párocos da Freguesia de Santo Antonio do Urubu de baixo

\begin{tabular}{|l|l|l|}
\hline \multicolumn{1}{|c|}{ Scriptor } & \multicolumn{1}{|c|}{ Cargo/função } & $\begin{array}{c}\text { Período de } \\
\text { atuação }\end{array}$ \\
\hline Joam da Silva Ribeiro & Vigário Colado & $1719-1728$ \\
\hline Joachim de Souza & Vigário Encomendado & $1728-1729$ \\
\hline Gonçallo Vellozo de Souza & Coadjutor & $1729-1735$ \\
\hline João Gomes de Souza & Vigário Colado & $1733-1746$ \\
\hline José da Silva Gomes & Vigário Encomendado & $1746-1751$ \\
\hline Manoel de Oliveira Cabo & Coadjutor & $1749-1757$ \\
\hline Joachim Marques de Oliveira & Vigário Encomendado & $1751-1753$ \\
\hline Manoel Pinto Rabello & Coadjutor & 1753 \\
\hline
\end{tabular}

Fonte: Elaborado pelos autores

Os scriptores pertenciam a uma elite instruída naquele microcosmo social, homens de idade adulta, e seguiam um modelo de escrita estruturado nas tradições do Sagrado Concílio Tridentino (1545-1563) e nas Primeiras Constituições do Arcebispado da Bahia (1719). Apesar de seguirem uma estrutura preestabelecida, os scriptores revelavam, nos registros paroquiais, a realidade da sociedade daquele tempo e espaço, inclusive características do estado da língua portuguesa, representadas por aspectos filológico-paleográficos e fenômenos linguísticos visíveis no texto. Os manuscritos expressam detalhes da sociedade da época, valores, cultura e costumes do sertão do Rio São Francisco e possibilitam a leitura de informações nas entrelinhas, por meio do testemunho indireto dos scriptores, materializado no texto manuscrito.

Quanto à metodologia, foi utilizada a pesquisa documental, mediante leitura da reprodução fac-símile e da transcrição do manuscrito, atendendo às orientações de Spina (1997) e Cambraia (2005). Posteriormente, as abreviaturas foram sistematizadas com o auxílio do programa computacional aplicado à Terminologia AntConc (2011) e consulta às obras de referência, como Bluteau (1728), Vieira (1871) e Flexor (2008), para verificar se as abreviaturas encontradas correspondiam às descrições que as obras apresentam.

\section{Levantamento e estudo das abreviaturas}

A partir do levantamento realizado no corpus, classificamos as abreviaturas com base em Berwanger e Leal (2008) e Flexor (2008), observando os variados aspectos que compõem os achados deste estudo, os quais apresentaremos a seguir. 
O sistema de abreviaturas por siglas foi representado pela letra inicial apenas, ou pela letra inicial e sinais abreviativos, como o ponto, dois-pontos ou apóstrofo. É o que mostra a Tabela 1:

Tabela 1: Abreviaturas por siglas.

\begin{tabular}{ccc}
\hline Abreviatura & Desenvolvimento & Ocorrências \\
V. & verso & 01 \\
D. & Doutor & 02 \\
D. & Dom & 02 \\
D. & Dona & 05 \\
D: & Dona & 02 \\
F & folha & 01 \\
N. & Nossa & 43 \\
N: & Nossa & 03 \\
P & por & 30 \\
p' & por & 03 \\
Q & Que & 55 \\
q' & que & 07 \\
S: & Santo & 03 \\
S: & Santa & 05 \\
S. & Santo & 09 \\
S. & São & 10 \\
S & Santo & 02 \\
\hline
\end{tabular}

Fonte: Elaborado pelos autores.

Entre os sinais abreviativos, o ponto (.) foi encontrado na maioria das palavras abreviadas. Os dois-pontos (:) foram utilizados apenas pelos scriptores Joam da Silva Ribeiro nos 36 assentos redigidos por suas mãos e Joam Gomes de Souza em 52 registros de casamentos.

Como mostra a Tabela 2, o sinal abreviativo apóstrofo (') foi utilizado em p' (Ex.: Solemnemente p' palavras de prezente) e q' (Ex.: de q' tudo fis este aSento no mesmo dia), além de outras ocorrências encontradas, a exemplo dos patronímicos (Ex.: Mrz', Frz', Glz') e do pronome de tratamento Snr' (Senhor).

Apenas nos registros de casamentos feitos pelo Vigário Joam Gomes de Souza, o sinal abreviativo apóstrofo (') foi utilizado para indicar a nasalidade, substituindo a letra $<\mathrm{m}>$ na separação de sílaba no final da linha (Ex.: nesta Freguezia de Santo Antonio do Urubu Co' Antonia de Lopes Tavareda; na forma do Sagr. Co' | C: Trid: ; feitas as denunciaçoes dos co' | traentes; emoradora Se' | Sedescobrir impedimento; de mil eSete Se' | tos e quarenta eSeis) e em uma nota à margem esquerda do verso do fólio 62, utilizada para informar os nomes dos nubentes, encontramos a utilização do apóstrofo para indicar a nasalização, substituindo o

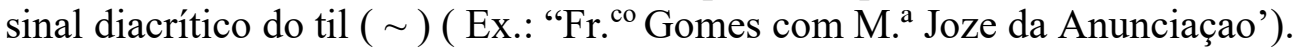

Além dos párocos responsáveis pela freguesia, o livro era utilizado pelo Comissário Visitador que registrava os vistos de visitas e em uma dessas anotações, no verso do fólio 15, encontramos mais dois exemplos do uso do apóstrofo para indicar a nasalização: " eordeno Sedeclara amarge' | deles" e "Se assine' as $\mathrm{fl}^{\text {as" }}$.

Ao conferirmos o Vocabulario Portuguez e Latino de Rafael Bluteau (1728), encontramos instruções que identificam as seguintes abreviaturas: "D", utilizada para Dom, Dona ou Doutor (p. 358); a letra S indica a abreviatura de Santo ou Santa (p. 362) e a letra "V" pode representar veja, verso, vossa e vosso. Encontramos no corpus dois exemplos de letras reduplicadas "R.R”, que significa o plural de Reverendos (Ex.: na Igreja de Sam Pedro 
damissam dos $\mid$ R.R. P. ${ }^{\text {es }}$ Capuxinhos - fl. 10v.; Como Consta das Certidoes dos R.R. Parochos que tenho emmeu poder - fl. 11r.).

Outro recurso habitual, utilizado pelos scriptores, foi a suspensão ou apócope, cuja palavra abreviada apresenta-se inacabada, devido à supressão dos elementos finais, como demonstra a Tabela 2:

Tabela 2: Abreviaturas por suspensão ou apócope.

\begin{tabular}{ccc}
\hline Abreviatura & Desenvolvimento & Ocorrências \\
Com C: & concílio & 2 \\
Conc. & concílio & 64 \\
Consti : & constituições & 3 \\
Constit. & constituições & 2 \\
escr. & escravo & 4 \\
fl & folha & 1 \\
Fr. & Frei & 2 \\
Sagr: & Sagrado & 20 \\
Sarg. Mor & Sargento Mor & 2 \\
Serg. & Sergipe & 1 \\
Trid & Tridentino & 4 \\
Trid. & Tridentino & 63 \\
Trid: & Tridentino & 36 \\
\hline
\end{tabular}

Fonte: Elaborado pelos autores.

No sistema por suspensão ou apócope, observamos a predominância de abreviaturas em palavras mais extensas, de três ou quatro sílabas, e apenas em uma palavra de duas e uma sílaba, "folha" e "Frei".

Vejamos agora as abreviaturas por contração ou síncope, presentes no manuscrito estudado, cujas palavras são abreviadas conservando a primeira ou primeiras letras e a última ou últimas. Eis os achados na Tabela 3:

Tabela 3: Abreviaturas por contração ou síncope.

\begin{tabular}{ccc}
\hline Abreviatura & Desenvolvimento & Ocorrências \\
Alfrz' & Alferes & 13 \\
Alfs' & Alferes & 1 \\
Alvres & Alvares & 15 \\
Alz' & Alvares & 11 \\
Frz' & Fernandes & 28 \\
Glz' & Gonçalves & 35 \\
Miz & Munis & 2 \\
Miz' & Munis & 1 \\
Mrr' & Moreira & 1 \\
Mrz' & Martins & 2 \\
Nnz' & Nunes & 2 \\
Roiz & Rodrigues & 10 \\
Roiz' & Rodrigues & 36 \\
Snr & Senhor & 1 \\
Snr' & Senhor & 2 \\
\hline
\end{tabular}

Fonte: Elaborado pelos autores. 
As abreviaturas por contração ou síncope foram recorrentes na fonte documental, e na maioria dos casos, foram utilizadas para os patronímicos com a terminação es, sinalizadas pela letra $z$ ao final da forma abreviada. O uso da letra duplicada no exemplo 'Mrr' (Moreira) não indica plural, como foi mencionado anteriormente, mas sim, pela utilização da letra por duas vezes na palavra.

Os exemplos de abreviaturas por contração ou síncope mais encontrados no corpus mantiveram as primeiras letras e as últimas e, em seguida, as formas abreviadas com as letras iniciais, intermediárias e finais, como em Mrz' (Martins), Nnz' (Nunes), Snr (Senhor) e Snr' (Senhor). Não encontramos nenhuma ocorrência com a forma abreviada utilizando apenas duas letras, a primeira e a última, salvo, em exemplos com letras sobrescritas, que veremos a seguir.

Uma outra tendência no sistema de abreviaturas utilizado pelos scriptores foi o uso das letras sobrescritas. Predominante no corpus, esse recurso utiliza uma pequena letra acrescentada por cima da abreviatura, normalmente no final da palavra. Vejamos alguns exemplos na Tabela 4.

Tabela 4: Abreviaturas por letras sobrescritas.

\begin{tabular}{|c|c|c|}
\hline Abreviatura & Desenvolvimento & Ocorrências \\
\hline Ajud. $^{\mathrm{e}}$ & Ajudante & 1 \\
\hline Alex. $^{\mathrm{e}}$ & Alexandre & 11 \\
\hline Alm. ${ }^{\mathrm{a}}$ & Almeida & 1 \\
\hline An. ${ }^{\text {de }}$ & Andrade & 1 \\
\hline An. $^{\text {to }}$ & Antônio & 9 \\
\hline Andr. ${ }^{\mathrm{e}}$ & Andrade & 6 \\
\hline Ant. ${ }^{a}$ & Antônia & 20 \\
\hline Ant. $^{\circ}$ & Antônio & 111 \\
\hline $\mathrm{An}^{\text {to }}$ & Antônio & 31 \\
\hline Ar. $^{\circ}$ & Araújo & 3 \\
\hline Arcebis. ${ }^{\text {do }}$ & Arcebispado & 1 \\
\hline Arcebp. ${ }^{\text {do }}$ & Arcebispado & 1 \\
\hline $\mathrm{B}^{\mathrm{a}}$ & Bahia & 8 \\
\hline B. $^{\text {do }}$ & Bernardo & 1 \\
\hline Bapt. $^{\text {a }}$ & Baptista & 1 \\
\hline Ber. $^{\text {do }}$ & Bernardo & 1 \\
\hline $\mathrm{Br}^{\mathrm{a}}$ & Brazida & 1 \\
\hline $\mathrm{Br}^{\text {co }}$ & Branco & 1 \\
\hline $\mathrm{Br} .^{\mathrm{da}}$ & Brazida & 3 \\
\hline $\mathrm{bx}^{\mathrm{o}}$ & Baixo & 21 \\
\hline C. ${ }^{1}$ & Coronel & 1 \\
\hline Caldr. ${ }^{a}$ & Caldeira & 1 \\
\hline Cap. $^{\text {am }}$ & Capitão & 9 \\
\hline cap. $^{\mathrm{m}}$ & Capitão & 9 \\
\hline cap $^{\mathrm{m}}$ & Capitão & 1 \\
\hline Capp. ${ }^{\mathrm{am}}$ & Capitão & 4 \\
\hline Capp. $^{\mathrm{m}}$ & Capitão & 1 \\
\hline Carv. $^{\circ}$ & Carvalho & 3 \\
\hline Castelobr. ${ }^{\text {co }}$ & Castelo Branco & 2 \\
\hline Castlbr. $^{\circ}$ & Castelo Branco & 2 \\
\hline Cazam. ${ }^{\text {tos }}$ & cazamentos & 2 \\
\hline $\mathrm{Ci}^{\text {de }}$ & Cidade & 1 \\
\hline
\end{tabular}


Volume 16 - Número 1 - jan/jul de 2021

\begin{tabular}{|c|c|c|}
\hline Cid. $^{e}$ & Cidade & 3 \\
\hline Col. ${ }^{\text {do }}$ & Colado & 2 \\
\hline Comis. ${ }^{\text {rio }}$ & comissário & 1 \\
\hline Comisr. ${ }^{\circ}$ & comissário & 1 \\
\hline Comp. ${ }^{\mathrm{a}}$ & Companhia & 1 \\
\hline d. ${ }^{\mathrm{a}}$ & Dita & 1 \\
\hline D. ${ }^{\text {as }}$ & Domingas & 2 \\
\hline D. ${ }^{\text {or }}$ & Doutor & 19 \\
\hline D. ${ }^{\text {os }}$ & Domingos & 19 \\
\hline $\mathrm{bx}^{\mathrm{o}}$ & Baixo & 1 \\
\hline debx. $^{\circ}$ & Debaixo & 9 \\
\hline def. $^{\text {ta }}$ & defunta & 1 \\
\hline Dez. ${ }^{\text {or }}$ & dezembargador & 1 \\
\hline Dezr. $^{0}$ & Dezembro & 1 \\
\hline dilig. ${ }^{\text {cas }}$ & diligências & 1 \\
\hline exm. $^{\circ}$ & excelentíssimo & 1 \\
\hline encerram. ${ }^{\text {to }}$ & encerramento & 1 \\
\hline encom. ${ }^{\text {do }}$ & encomendado & 2 \\
\hline
\end{tabular}

Fonte: Elaborado pelos autores.

As abreviaturas listadas na Tabela 4 representam alguns dos 198 tipos de diferentes palavras abreviadas, encontradas no corpus, utilizando o sistema de letra sobrescrita. Algumas delas de forma muito repetida, como é o caso, por exemplo, de Ant. ${ }^{\circ}$ (111), freg. ${ }^{a}$ (135), M. ${ }^{\mathrm{a}}$ (106), fey ${ }^{\text {tas }}(55)$, entre outras.

Os substantivos comuns (71 palavras diferentes) e os antropônimos (78) apresentaram uma alta recorrência de abreviação em comparação aos adjetivos (13), advérbios (6) e preposições (2). Os pronomes de tratamento (28) foram abreviados em quase todas as vezes que apareceram nos textos, provavelmente pela formação mais extensa da maioria deles, a

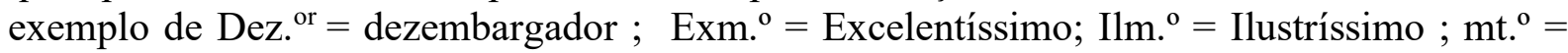
Meritíssimo; R. ${ }^{\mathrm{mo}}=$ Reverendíssimo.

Por fim, temos os casos que Pereira e Telles (1982) denominam polissemia e parassinonímia. As autoras classificam de polissemia o uso do mesmo recurso para abreviar palavras distintas. Vejamos alguns exemplos expostos no Quadro 2:

Quadro 2: Abreviatura polissêmica

\begin{tabular}{|l|l|l|l|l|}
\hline Abreviatura & Desenvolvimento & \multicolumn{1}{|c|}{ Contexto } & $\begin{array}{l}\text { Ano / } \\
\text { fólio }\end{array}$ & Scriptor \\
\hline D. & Dona & $\begin{array}{l}\text { ocapitaõ Mor Antonio de Sâ e } \\
\text { Luna viuvo, q ficou de D. } \\
\text { Mariana daSylva }\end{array}$ & $\begin{array}{l}1730, \\
13 \mathrm{v} .\end{array}$ & $\begin{array}{l}\text { Gonçallo } \\
\text { Vellozo de } \\
\text { Souza }\end{array}$ \\
\hline D. & Dom & $\begin{array}{l}\text { Sendo prezentes p testemunhas } \\
\text { ocapitaõ D. Jozeph } \mid \text { de Souza e } \\
\text { Manoel Cardozo do Rozario }\end{array}$ & $\begin{array}{l}1731 \\
18 \mathrm{r} .\end{array}$ & $\begin{array}{l}\text { Gonçallo } \\
\text { Vellozo de } \\
\text { Souza }\end{array}$ \\
\hline D. & Doutor & $\begin{array}{l}\text { de q foy Sua Ex. }{ }^{\text {a }} \text { Rm. }{ }^{\text {do }} \text { D. q Sera } \\
\text { mandar nova despen } \mid \text { ssa q em } \\
\text { meo poder fica }\end{array}$ & $\begin{array}{l}1745 \\
58 \text { v. }\end{array}$ & $\begin{array}{l}\text { Joam } \\
\text { Gomes de } \\
\text { Souza }\end{array}$ \\
\hline L. ${ }^{\text {ca }}$ & Lourença & Thome Ramos com L. ${ }^{\text {ca }}$ Roiz' & 1748, & $\begin{array}{l}\text { Jozê da } \\
\text { Silva } \\
\text { Gomes }\end{array}$ \\
\hline
\end{tabular}


Volume 16 - Número 1 - jan/jul de 2021

\begin{tabular}{|c|c|c|c|c|}
\hline L.ça & Licença & $\begin{array}{l}\text { em prezença do R. }{ }^{\text {do }} \text { Coadjutor } \\
\text { oL. do | Gonçallo Vellozo deSouza } \\
\text { de L. } .^{\text {ca }} \text { minha, }\end{array}$ & $\begin{array}{l}1737 \\
43 \mathrm{v} .\end{array}$ & $\begin{array}{l}\text { Joam } \\
\text { Gomes de } \\
\text { Souza } \\
\end{array}$ \\
\hline $\mathrm{S}:$ & $\mathrm{S} \tilde{a} o$ & $\begin{array}{l}\text { enatural | daCidade doporto; } \\
\text { Freguezia deS: Nicolao; }\end{array}$ & $\begin{array}{l}1739, \\
45 \mathrm{v} .\end{array}$ & $\begin{array}{l}\text { Joam } \\
\text { gomes de } \\
\text { Souza } \\
\end{array}$ \\
\hline S: & Senhora & $\begin{array}{l}\text { onde he natural da Freguezia de } \\
\mathrm{N}: \text { S: do Ó | do Bispado } \\
\text { depernambuco }\end{array}$ & $\begin{array}{l}1744 \\
55 \mathrm{r}\end{array}$ & $\begin{array}{l}\text { Joam } \\
\text { Gomes de } \\
\text { Souza } \\
\end{array}$ \\
\hline $\mathrm{S}:$ & Santo & $\begin{array}{l}\text { nesta Freg. }{ }^{\text {a }} \text { de S: } \text { Ant. }^{\text {o }} \text { do Urubu } \\
\text { do Rio de bayxo }\end{array}$ & $\begin{array}{l}1744 \\
55 \mathrm{r}\end{array}$ & $\begin{array}{l}\text { Joam } \\
\text { Gomes de } \\
\text { Souza }\end{array}$ \\
\hline
\end{tabular}

Fonte: Elaborado pelos autores.

Os resultados mostraram que as abreviaturas polissêmicas presentes nos assentos de casamentos se ajustam ao contexto do uso da palavra, embora Pereira e Telles (1982) chamam a atenção para a problemática da polissemia e da parassinonímia que podem dar margem à diversas interpretações.

As palavras abreviadas presentes no Quadro 2 também aparecem por extenso nos registros. O pronome de tratamento Dona ocorre em 05 registros, Dom em 06 e a palavra Doutor, por extenso, não foi encontrado no corpus. As demais palavras Liçença (37), Licenssa (06), Lourença (05), Sam (238), Saõ (03), Senhora (42) também foram grafadas por extenso ao longo do manuscrito. Observamos, portanto, que os scriptores preferiam utilizar antes dos nomes de santos a palavra "Sam" usando o $m$ para indicar a nasalidade, ao invés de "Saõ", sendo esta utilizada apenas por 03 vezes pelo Vigário Gonçallo Velloso de Souza (Ex.: debx. ${ }^{\circ}$ do Rio de Saõ Francisco - f.14v. ; Santo Antonio do Urubû debayxo do Rio deSaõ Fr. ${ }^{\text {co }}$ f.15v.; Antonio do Urubû de bx ${ }^{\circ}$ do Rio de Saõ Francisco - f.26v.). A grafia "saõ" foi utilizada preferencialmente para grafar o verbo ser, aparecendo em 71 ocorrências (Ex.: donde | os Contraentes Sã̃ naturais emoradores, - f. 69r.).

No Dicionário de Abreviaturas manuscritos dos séculos XVI ao XIX de Flexor (2008), a autora registra 35 palavras diferentemente abreviadas pela mesma sigla D (D.; D:; D'), 32 formas de abreviar a palavra licença, 03 ocorrências para o antropônimo Lourença (Lour ${ }^{\mathrm{a}}$; Lour $^{\mathrm{ca}}$; Lour ${ }^{\mathrm{ca}}$ ) e 42 abreviaturas com a sigla $\mathrm{S}$ para denominar diferentes palavras.

No caso do fenômeno da parassinonímia (PEREIRA; TELES, 1982), a forma abreviada da mesma palavra é grafada de distintas formas. Tratam-se principalmente de abreviaturas por letra sobreposta, como se pode ver no Quadro 3.

Quadro 3: Abreviaturas Parassinonímias.

\begin{tabular}{|c|c|}
\hline Palavra & abreviaturas \\
\hline Alferes & Alfrz' / Alfs' \\
\hline Alvares & Alvres / Alz' \\
\hline Antonio & $\mathrm{An}^{\text {to }} / \mathrm{Ant}^{\mathrm{o}} / \mathrm{An}^{\text {to }}$ \\
\hline Arcebispado & Arcebis. $^{\text {do }} /$ Arcebp. $^{\text {do }}$ \\
\hline Bernardo & B. ${ }^{\text {do }} /$ Ber. $^{\text {do }}$ \\
\hline Brazida & $\mathrm{Br}^{\mathrm{a}} / \mathrm{Br}^{\mathrm{da}}$ \\
\hline Capitão & 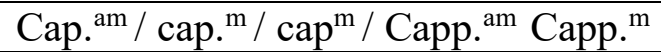 \\
\hline Castelo Branco & Castelobr. $^{\text {co }} /$ Castlbr. $^{\circ}$ \\
\hline cidade & Ci. ${ }^{\mathrm{de}} / \mathrm{Cid}^{\mathrm{e}}$ \\
\hline Comissário & Comis. $^{\text {rio }} /$ Comisr. $^{\circ}$ \\
\hline
\end{tabular}


Volume 16 - Número 1 - jan/jul de 2021

\begin{tabular}{|c|c|}
\hline Concílio & Com C: / Conc. \\
\hline Constituições & Consti : / Constit. \\
\hline Excelência & $\mathrm{Ex}^{\mathrm{a}}{ }^{\mathrm{a}} \mathrm{Ex} .{ }^{\mathrm{ca}}$ \\
\hline Excelentíssimo & Exm. $^{\circ} /$ Ex. $^{\mathrm{mo}}$ \\
\hline folha & $\mathrm{f} / \mathrm{fl}$ \\
\hline Francisca & Fr. $^{\text {ca }} /$ Fran. $^{\text {ca }}$ \\
\hline Francisco & Fr. $^{\mathrm{co}} /$ Fran. $^{\mathrm{co}} /$ Fran. $^{\mathrm{o}} / \mathrm{Fr}^{\mathrm{co}}$ \\
\hline geral & g. ${ }^{\mathrm{al}} / \mathrm{g} .{ }^{1} / \mathrm{g}^{\mathrm{al}}$ \\
\hline Gonçalves & $\mathrm{Gl}^{\mathrm{es}} / \mathrm{Glz}$ \\
\hline impedimento & impedim. $.^{\text {to }} /$ impedimt. $^{\text {o }} /$ impedim $^{\text {to }}$ \\
\hline Lourença & L. ${ }^{\text {ca }} /$ Lr. $^{\text {ca }}$ \\
\hline Meritíssimo & M. $/ \mathrm{Ms}^{\mathrm{o}} / \mathrm{mt}^{\mathrm{o}}$ \\
\hline Munis & Miz / Miz' \\
\hline natural & $\mathrm{n}^{\text {al }} /$ natur. $^{1}$ \\
\hline Nossa & N. / N: \\
\hline Oliveira & Olivr. $^{\text {a }}$ / OLivr. ${ }^{\text {a }}$ / Olivr ${ }^{\mathrm{a}}$ \\
\hline Pernambuco & Pern. $.^{\text {co }} /$ Pern $^{\text {co }}$ \\
\hline presentes & prez. $^{\text {es }} /$ prez. $^{\text {te }} /$ prez. $^{\text {tes }}$ \\
\hline que & $\mathrm{q} / \mathrm{q}^{\prime}$ \\
\hline Reverendíssimo & $\mathrm{R}^{\mathrm{mo}} / \mathrm{Rm}^{\mathrm{o}}$ \\
\hline Reverendo & R. / R.R. / R. ${ }^{\text {do }}$ \\
\hline Sagrado & Sag. / Sagr: \\
\hline Santa & $\mathrm{S} .^{\text {ta }} / \mathrm{S}:$ \\
\hline Santo & $\mathrm{S} / \mathrm{S} . / \mathrm{S}: / \mathrm{S}^{\text {to }} / \mathrm{St}^{\circ}$ \\
\hline Santos & $\mathrm{S}^{\text {os }} /{\mathrm{S} . \mathrm{t}^{\mathrm{os}} / \mathrm{St}^{\mathrm{os}}}$ \\
\hline Senhor & S. $^{\text {r } / \text { Snn. }}{ }^{\circ} /$ Snr / Snr’ \\
\hline Senhora & Sr. $^{\text {a }}$ Snar. ${ }^{a} /$ Snr. $^{a}$ \\
\hline sentença & $\mathrm{Sn}^{\mathrm{ca}}$ / Snn. ${ }^{\mathrm{a}} / \mathrm{Snn} .^{\mathrm{ca}} / \mathrm{Snn}^{\mathrm{ca}} / \mathrm{Srn}^{\mathrm{a}}$ \\
\hline Siqueira & Siqr. $^{\mathrm{a}} /$ Siqr $^{\mathrm{a}}$ \\
\hline solenemente & $\begin{array}{c}\text { Solemmt. }^{\mathrm{e}} / \text { Solemnem. }^{\text {te }} / \text { Solemnem }^{\text {te }} / \\
\text { Solenemt. }\end{array}$ \\
\hline Teixeira & Teix. $^{\mathrm{a}} /$ Teixr. $^{\mathrm{a}}$ \\
\hline Tridentino & Trid / Trid. / Trid: \\
\hline Vasconcelos & Vas. ${ }^{\text {los } / \text { Vasc. }}{ }^{\text {os }}$ \\
\hline verdade & ver. $^{\text {de }} /$ verd. $^{\mathrm{e}}$ \\
\hline vigário & Vig. ${ }^{\text {rio } / \text { Vigr. }}$ / Vigro \\
\hline
\end{tabular}

Fonte: Elaborado pelos autores

Os resultados mostraram que, em 45 palavras ocorreram o fenômeno da parassinonímia, apresentando de duas a cinco formas de abreviar a mesma palavra. Essa quantidade encontrada no corpus pode parecer inexpressiva se comparada com os achados de Flexor (2008). Para citar alguns poucos exemplos, a autora registrou 93 abreviaturas diferentes para a palavra alferes, 436 formas para capitão e 447 para reverendo(s). Esse fato comprova a problemática apresentada por Pereira e Teles (1982) referente à apresentação de várias combinações representando uma única palavra e também pela forma que uma abreviatura pode representar diversas palavras. 


\section{Considerações finais}

Os dados apresentados neste trabalho levam a crer que os scriptores seguiram as tendências da época em que o documento foi produzido. A análise do manuscrito mostrou a liberdade de abreviar, motivada pela ausência de normatização, o que levava à hesitação gráfica no momento da escrita.

A classificação proposta por Berwanger e Leal (2008) e Flexor (2008) estão listadas nos assentos de casamentos, salvo as notas tironianas que não foram encontradas no corpus devido ao recorte temporal. A respeito do uso dos pontos abreviativos, predominaram o uso do ponto, seguido do apóstrofo e em menor escala, o uso dos dois pontos. Mesmo que os scriptores tenham utilizado diversas formas para abreviar, encontramos as palavras correspondente escritas por extenso ao longo do documento.

As frequências listadas que mais ocorreram na fonte foram as abreviaturas com letras sobrescritas, uma vez que algumas formas são mais recorrentes pelo fato de que quanto maior a frequência de uma determinada palavra, maior a possibilidade de abreviatura.

Os demais tipos de abreviaturas também tiveram presença marcante no manuscrito, apresentando desde as formas mais simplificadas como as siglas, representadas por uma única letra ou pelas palavras inacabadas da suspensão ou apócope e também pelo processo de abreviar as primeiras e últimas letras, do sistema de contração ou síncope. De todas as formas, a abreviatura alfanumérica, combinando letras e números, apresentou apenas uma ocorrência.

Algumas palavras têm mais de uma forma de abreviatura, a exemplo de Antônio $\left(\right.$ An. ${ }^{\text {to }}$; Ant. ${ }^{o}$; An $^{\text {to }}$ ) e Francisco $\left(\mathrm{Fr}^{\mathrm{co}}{ }^{\mathrm{c}}\right.$ Fran. ${ }^{\mathrm{co}}$; Fran..$^{\mathrm{o}}$; $\left.\mathrm{Fr}^{\mathrm{co}}\right)$, o que nos leva a inferir que quanto maior a extensão da palavra, maior possibilidade de variação na forma de abreviar, enquanto que, uma palavra mais curta, como o adjetivo baixo, apareceu de forma abreviada em 22 ocorrências sem variações $\left(b^{0}\right)$. As variações foram encontradas em grafias escritas até pelos mesmos punhos, evidenciando a falta de normatização para a utilização das abreviaturas, além da hesitação do scriptor ao escolher uma forma ou outra, caracterizando, assim, os fenômenos léxico-semânticos da polissemia e da parassinonímia.

Nos assentos de casamentos estudados, o uso do sistema de abreviaturas reflete o princípio da economia, seguindo características sócio-históricas da época em que foram escritos, embora o uso de formas abreviadas fossem contrárias às normas das Constituições Primeiras do Arcebispado da Bahia (1719), que exigiam que os assentos fossem exarados com clareza, inteligíveis, por extenso e sem algarismos.

\section{Referências}

Fonte manuscrita:

Livro n. ${ }^{0} 1$ de Registros de Batizados da Freguesia de Santo Antônio do Urubu de Baixo (1719-1953). Arquivo da Cúria Diocesana de Bom Jesus da Lapa - Bahia.

Fontes impressas e eletrônicas:

ACIOLI, V. L. C. A escrita no Brasil Colônia: um guia para leitura de documentos manuscritos. Recife: FUNDAJ, Editora Massangana; UFPE, Editora Universitária, 1994. ANTHONY, L. Lawrence Anthony Website (AntConc). Disponível em: http://www.antlab.sci.waseda.ac.jp/index.html. 2011. Acesso em: 16 fev. 2021. 
Volume 16 - Número 1 - jan/jul de 2021

BERWANGER, A. R; LEAL, J. E. F. Noções de Paleografia e Diplomática. Santa Maria: Editora UFSM, 2008.

BLUTEAU, R. Vocabulario portuguez \& latino: aulico, anatomico, architectonico ... Coimbra: Collegio das Artes da Companhia de Jesus, 1728.8 v. Disponível em: http://purl.pt/13969. Acesso em: 10 mar. 2021.

CAMBRAIA, C. N. Introdução à crítica textual. São Paulo: Martins Fontes, 2005. CONSTITUIÇÕES primeyras do Arcebispado da Bahia feytas, \& ordenadas pelo Illustrissimo e Reuerendissimo Sor D. Sebastião Monteyro da Vide, Arcebispo do Arcebispado, \& do Conselho de Sua Magestade, propostas e acceytas em o Sinodo Diocesano que o dito Senhor celebrou em 12 de junho do anno de 1707. Lisboa Occidental: na Officina de Paschoal da Sylva, Impressor de Sua Majestade, 1719. FLEXOR, M. H. O. Abreviaturas: manuscritos dos séculos XVI ao XIX. 3. Ed. Rio de janeiro: Arquivo nacional, 2008.

LEAL, J. E. F. Glossário de Paleografia. Rio de Janeiro: ABB. 1994.

MARCOTULIO, L. L. et al. Filologia, História e Língua: olhares sobre o português medieval. São. Paulo: Parábola, 2018.

NÚÑEZ CONTRERAS, L. Manual de Paleografía. Fundamentos e historia de la escritura latina hasta el siglo VIII. Madrid, Cátedra, 1994.

PEREIRA, T. L. G.; TELLES, C. M. A problemática concernente ao desenvolvimento de abreviaturas. In: I SEMINÁRIO DE ARQUIVOLOGIA, 1982, Salvador: Universidade Federal da Bahia, 1982.

SÁNCHEZ PRIETO, A. B. Las abreviaturas como indicadores de hábitos de lectoescritura. Revista de História, Cárceres, p. 159-168, 2001

SPINA, S. Introdução à edótica: Crítica textual. São Paulo: Ars Poetica/ Editora da Universidade de São Paulo, 1997.

VIEIRA, F. D. Grande dicionário português: ou Tesouro da língua portuguesa. Porto, Portugal: Ernesto Chardron, Editor, Porto, Portugal: Bartolomeu H. de Moraes, 1871. http://bibdig.biblioteca.unesp.br/handle/10/28254 Acesso em 19 mar. 2021. 